Article

\title{
Effect of Holes on Dynamic Crack Propagation under Impact Loading
}

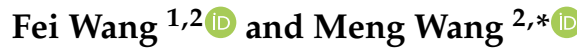 \\ 1 Failure Mechanics \& Engineering Disaster Prevention and Mitigation, Key Laboratory of Sichuan Province, \\ Sichuan University, Chengdu 610065, China; sirbuer@163.com \\ 2 Key Laboratory Deep Underground Science and Engineering (Ministry of Education), College of \\ Architecture and Environment, Sichuan University, Chengdu 610065, China \\ * Correspondence: wangmeng@scu.edu.cn; Tel.: +86-15928076774
}

Received: 17 November 2019; Accepted: 30 January 2020; Published: 7 February 2020

\begin{abstract}
In civil, geotechnical, and mining engineering, the investigation of the holes' effect on dynamic crack propagation is essential because it can be used to predict possible fracture and protect cracked structures being further damaged. In this paper, a specimen made from polymethyl methacrylate (PMMA) with a pre-crack and two holes was proposed, and the Split-Hopkinson pressure bar was employed to investigate the effect of holes on dynamic crack propagation under impact loading. Notably, the locations of the holes were well designed with different two-hole spacing $(12 \mathrm{~mm}, 16 \mathrm{~mm}$, and $20 \mathrm{~mm}$ ) and crack-hole distance $(15 \mathrm{~mm}, 30 \mathrm{~mm}$, and $45 \mathrm{~mm})$. Crack propagation gauges were applied to monitor the fracturing time and crack extending velocity. The interaction characteristic between the crack and two holes was studied numerically using the AUTODYN code. In the numerical models, the failure criteria of maximum tensile stress and softening damage were employed for brittle material. The crack path, the propagating velocity, the particle velocity vector, and the stress state between the holes were analyzed. The calculation results indicate that compressive stresses between the two holes induced by the deformation of the holes play a crucial role in confining the vertical crack propagation. Both experimental and numerical results demonstrate that the holes have a suppressing action on the moving crack; as the two-hole spacing decreases, the suppressing action intensifies.
\end{abstract}

Keywords: impact loading; crack propagation; crack arrest; PMMA; numerical simulation

\section{Introduction}

In civil engineering, geotechnical engineering, and mining engineering, the structure strength and the fracture properties are dominated by materials with several macro and micro defects, such as concrete, rock mass, and other construction building materials. Much attention is paid to investigating the defects' effect on crack propagation behaviors, with numerous experimental and numerical approaches conducted [1-8]. Among those defects, holes are universal defects in materials which are shaped naturally or designed for a specific function, such as blast holes, observation holes, pilot holes, etc. Under dynamic loading, the induced crack might propagate and encounter holes, and the crack propagation behaviors could be influenced by the interaction between the crack and holes. It is significant to investigate the crack-hole interaction and predict the crucial behaviors in the crack propagation process for engineering security and hazard mitigation.

In 1981, the propagation of a transverse crack with an opposite hole was investigated by Theocaris [9]. Benefitting from a caustics system collaborated with a high-speed camera, the results were uncovered that the crack momentarily arrests when arriving at the discontinuity, then reinitiates later with a different velocity. In 1988, Milios [10] studied crack propagation and crack-hole interaction 
under different dynamic loads with the caustics method, and the crack-hole interaction characterized by the process of attraction revealed that the repulsion of the crack toward the hole was interrupted by a momentary crack arrest at the hole boundary. In 2008, Murdani [11] proposed a technique to arrest crack initiation by drilling ancillary holes near the stop-drilled holes. The calculations demonstrated that the holes' effects could be applied in the crack arrest technical method. In 2015, Ayatollahi [12], conducted an experiment with an empty hole on a compact tension specimen to test crack initiation and growth under the hole's effect, pointing out that the stress concentration at the stop-hole edge was influenced by the loading condition and the diameter of the hole. In 2016, Chen [13] proposed that the hole's influence on cracks should be noted and showed a method for determining the appropriate size of a stop hole for cracked marine and offshore structures. In 2016, Yang [14] focused on investigating the crack-defect interaction mechanism of an empty hole before the pre-crack with a digital-laser dynamic caustics system, revealing the relationship between hole size and the dynamic stress intensity factor and the crack propagation behavior when the crack encounters a single hole. In 2017, with Wang's work [15], the effect of the original prefabricated hole on dynamic crack was investigated using an impact drop hammer combined with a dynamic caustics system. Polymethyl methacrylate (PMMA) specimens were employed in the experiment with the crack stress intensity factor and extending speed at the crack tip obtained for analysis.

However, the mechanism of holes on running cracks under dynamic loading is not very clear, and there still remain some unanswered or partially unanswered aspects. For example, how do the cracks and holes interact as they approach each other? What is the effect of the holes on the running cracks? Under what conditions would a running crack completely stop? Under what conditions would a running crack bifurcate to sub-cracks connecting with the holes? In this paper, a single-cleavage semi-circle specimen with a pre-crack and two empty holes is proposed to investigate the effect of the holes on crack propagation. Notably, the holes' locations with respect to the crack were well designed with different distance parameters to realized quantitative analysis. The Split-Hopkinson pressure bar (SHPB), along with crack propagation gauges (CPGs), was employed in the impact experiment, and the crack fracture phenomena and propagation velocity data were collected. Moreover, AUTODYN software [16-20] was introduced elaborately, and a numerical model was established using suitable damage criteria to study the mechanism of the holes' effect on crack propagation. With the experimental-numerical method, several crucial conclusions were obtained. The study on the effect of the holes on the propagating crack has essential engineering significance, and the investigation can be applied as a technique to arrest running cracks so as to protect some fundamental structures from being further damaged.

\section{Experiment}

The Split-Hopkinson pressure bar was employed to investigate dynamic crack propagation under the effect of holes [21,22]. The propagation behavior of a pre-crack on the single-cleavage semi-circle plate specimen was investigated, and the fracture velocity of the moving crack was detected using a crack propagation gauge.

\subsection{Test System and Specimen}

The Split-Hopkinson pressure bar test system applied in the experiment is shown in Figure 1, and the bars' parameters are listed in Table 1. 


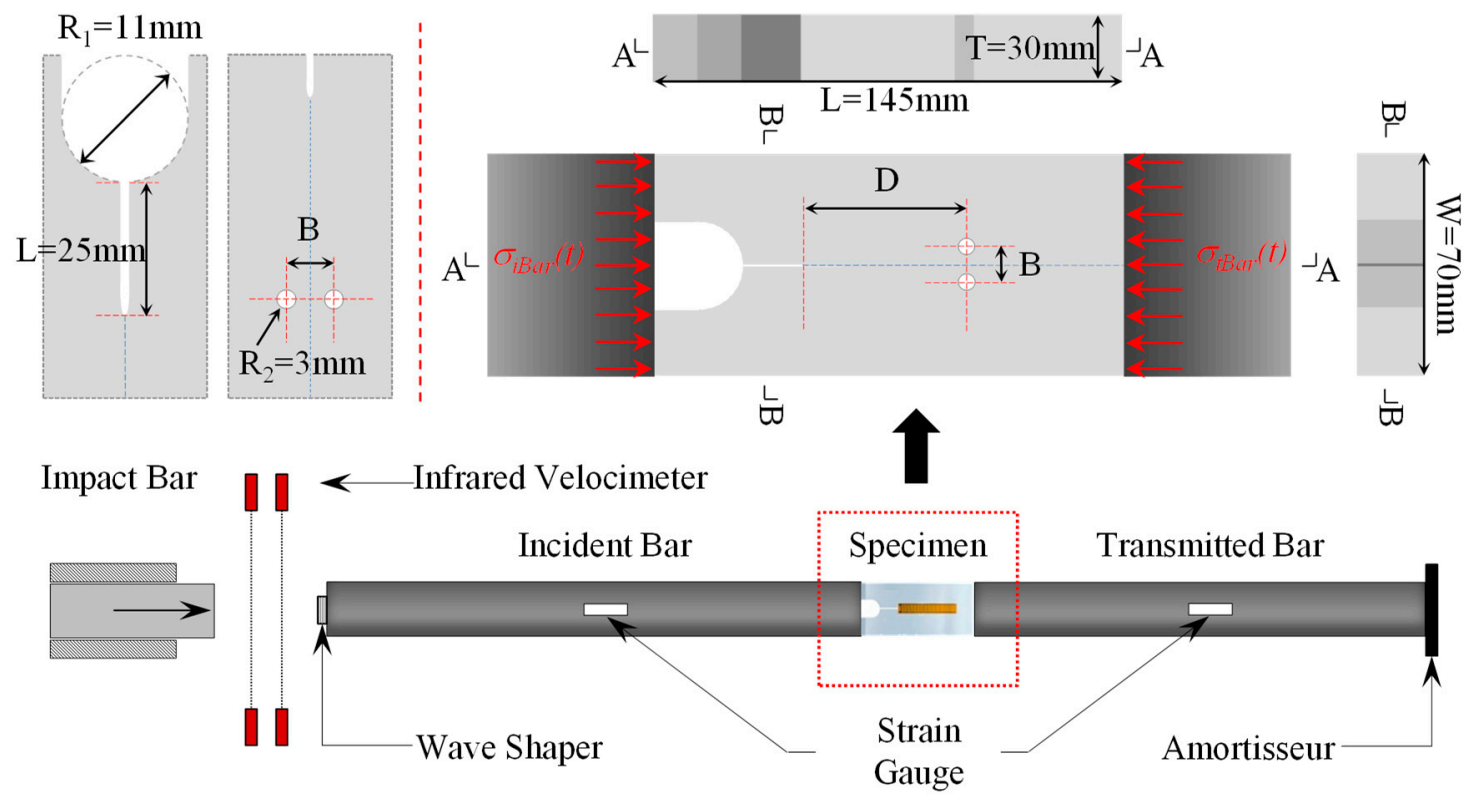

Figure 1. Split-Hopkinson pressure bar (SHPB) test system and specimen geometry.

Table 1. Material parameters of Split-Hopkinson pressure bar.

\begin{tabular}{ccccccc}
\hline Name & Material & $\begin{array}{c}\text { Length } \\
(\mathbf{m m})\end{array}$ & $\begin{array}{c}\text { Diameter } \\
(\mathbf{m m})\end{array}$ & $\begin{array}{c}\boldsymbol{\rho} \\
\left(\mathbf{k g} / \mathbf{m}^{\mathbf{3}}\right)\end{array}$ & $\mathbf{E}_{\mathbf{d}}(\mathbf{G P a})$ & $\boldsymbol{v}_{\mathbf{d}}$ \\
\hline Incident Bar & $40 \mathrm{CrmoV}$ & 3000 & 80 & 7600 & 210 & 0.25 \\
Transmitted Bar & $40 \mathrm{CrmoV}$ & 2000 & 80 & 7600 & 210 & 0.25 \\
\hline
\end{tabular}

The strain gauges were glued on the surface of the bars, and the voltage signal of the gauges could be collected using an ultra-dynamic strain amplifier, before being stored in the computer. With Equation (1) [23], one can gain the strain signals.

$$
\varepsilon=\frac{4 U_{0}}{n E_{g} K^{\prime}}
$$

where $\varepsilon$ is the strain, $U_{0}$ is the voltage recorded by the strain gauges, $E g$ is the bridge voltage, $K$ is the sensitivity coefficient of the strain gauges, and $n$ is the gain coefficient of the amplifier.

Then, the loads acting on the top and bottom of the specimen could be calculated using Equation (2).

$$
\begin{aligned}
& P_{i}(t)=A_{i} E_{d}\left[\varepsilon_{i}(t)+\varepsilon_{r}(t)\right] \\
& P_{t}(t)=A_{t} E_{d} \varepsilon_{t}(t)
\end{aligned}
$$

where $\varepsilon_{i}(t)$ and $\varepsilon_{r}(t)$ are the strains of the incident bar caused by the incident wave and reflected wave, respectively. Moreover, $\varepsilon_{t}(t)$ is the strain of the transmitted bar induced by the transmitted wave, $P_{i}(t)$ is the load on top of the specimen, and $P_{t}(t)$ is the load on the bottom of the specimen.

A single-cleavage semi-circle specimen with a pre-crack and two empty holes is proposed to investigate the holes' effect on extending the crack, as shown in Figure 1. The length of the pre-crack was $25 \mathrm{~mm}$ with its tip sharpened by a thin blade, and the diameter of the semi-circle was $22 \mathrm{~mm}$. There were two empty holes deployed symmetrically along the axis with two variables designed: $\mathrm{D}$ for distance from the crack tip to the middle point of the holes and B for distance between two holes. A total of nine types of specimens were investigated, as listed in Table 2. The initiation of the pre-crack under impact loading could be realized easily using the semi-circle on the top of the specimen, and sufficient space for crack propagation was left. The fracture behavior and characteristics of propagation 
could be detected elaborately, especially for the hole zone. Other geometric parameters were as follows: $145 \mathrm{~mm}$ in length, $70 \mathrm{~mm}$ in width, $30 \mathrm{~mm}$ in thickness, and $6 \mathrm{~mm}$ in diameter for an empty hole.

Table 2. Specimen nomenclature.

\begin{tabular}{cccc}
\hline Specimen & $\mathbf{D}=\mathbf{1 5} \mathbf{~ m m}$ & $\mathbf{D}=\mathbf{3 0} \mathbf{~ m m}$ & $\mathbf{D}=\mathbf{4 5} \mathbf{~ m m}$ \\
\hline $\mathrm{B}=12 \mathrm{~mm}$ & B12-D15 & B12-D30 & B12-D45 \\
$\mathrm{B}=16 \mathrm{~mm}$ & B16-D15 & B16-D30 & B16-D45 \\
$\mathrm{B}=20 \mathrm{~mm}$ & B20-D15 & B20-D30 & B20-D45 \\
\hline
\end{tabular}

Crack propagation gauges (CPGs) were employed in order to measure the crack propagation velocity, and a complete test system is shown in Figure 2. The CPG is a precise resistance gauge with resistance fine wires equally spaced on a glass-silk baseplate. Before CPGs were installed, the surface of the specimen was cleaned with ethyl alcohol. Then, superglue was used to tightly attach the CPG to the surface of the specimen, while the joints of the CPG were carefully connected to the wires. It is important to make sure that the resistance fine wires on the CPG are undamaged and that the CPG adequately covers the possible crack path; thus, all details were checked twice before collection. A step-by-step voltage signal could be collected by the oscilloscope as the fine resistance wire was fractured by the running crack. Thus, the exact time when the crack fractured each fine wire could be confirmed. Then, the average crack propagation velocity between the adjacent wires could be obtained as the distance divided by time, as the distance between adjacent fine wires was constant at $2 \mathrm{~mm}$.

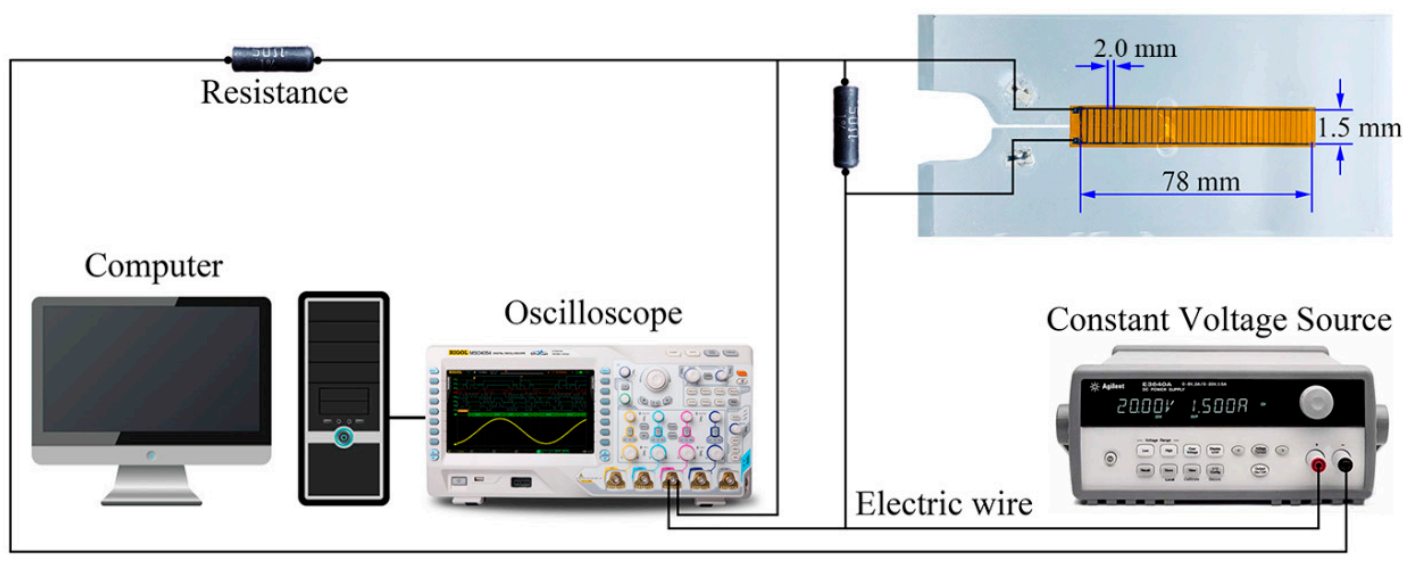

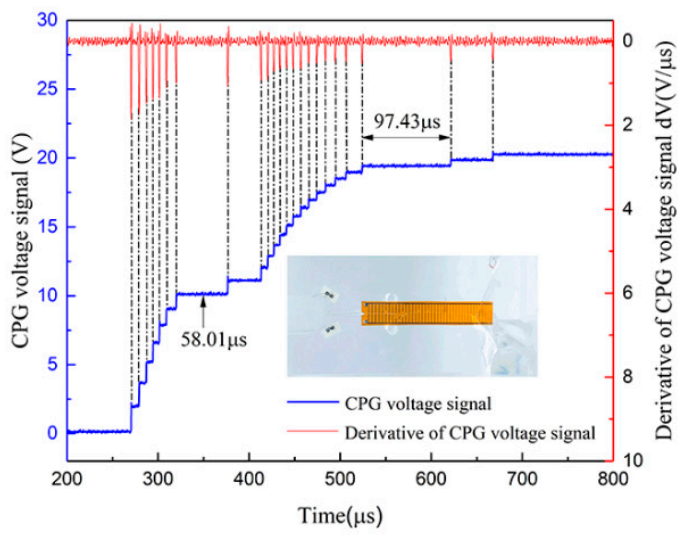

(a) The voltage signal of B16-D15 specimen.

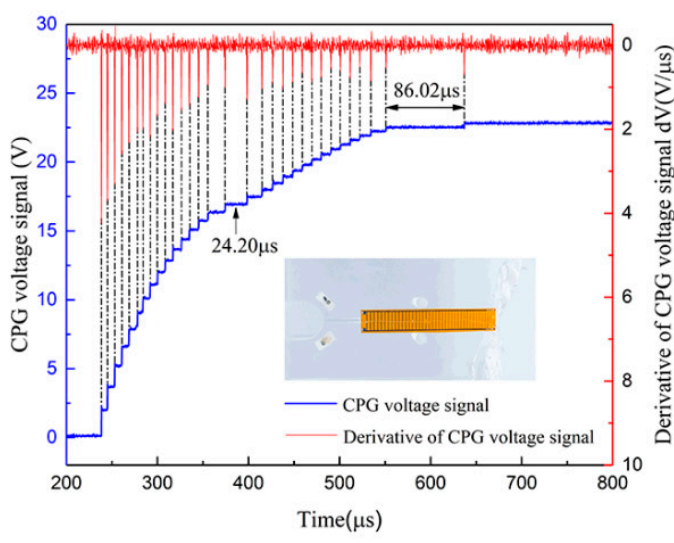

(b) The voltage signal of B20-D30 specimen.

Figure 2. Crack propagation gauge (CPG) test system and the voltage signal curves. (a) The voltage signal of B16-D15 specimen. (b) The voltage signal of B20-D30 specimen. 


\subsection{Material Parameters}

Polymethyl methacrylate (PMMA) is a universal building material widely utilized in engineering applications, and it performs well in investigation fracture research [24,25]. Under dynamic loading, PMMA has very similar fracture mechanical characteristics to brittle material, such as concrete and rock. Moreover, the fracture crack can be better observed in PMMA due to its transparency, and the random error can be reduced due to its homogeneity. Meanwhile, the accuracy of the specimens can be guaranteed, as PMMA is accurately manufactured using a laser. Therefore, PMMA was chosen, and its material parameters were measured. As Figure 3 shows, a PMMA cylinder, $100 \mathrm{~mm}$ in length and $50 \mathrm{~mm}$ in diameter, was used, and the longitudinal and transverse waves could be determined using a non-metallic acoustic detector. According to Equations (3) and (4) [26], $E_{d}$ (dynamic elastic modulus) and $v_{d}$ (Poisson's ratio) could be obtained, as listed in Table 3.

$$
\begin{gathered}
E_{d}=\frac{\rho C_{s}^{2}\left(3 C_{\mathrm{d}}^{2}-4 C_{s}^{2}\right)}{C_{d}^{2}-C_{s}^{2}}, \\
v_{d}=\frac{C_{d}^{2}-2 C_{s}^{2}}{2 C_{d}^{2}-2 C_{s}^{2}},
\end{gathered}
$$

where $C_{d}$ is the longitudinal wave velocity, $C_{S}$ is the transverse wave velocity, $E_{d}$ is the dynamic elastic modulus, $v_{d}$ is Poisson's ratio, and $\rho$ is the density.

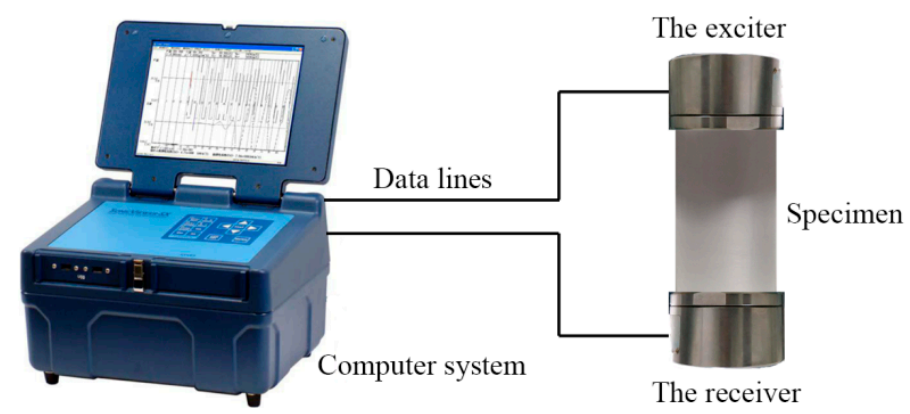

Figure 3. Non-metallic acoustic detector.

Table 3. Material parameters of polymethyl methacrylate (PMMA).

\begin{tabular}{ccccccc}
\hline Material & $\mathrm{C}_{\mathrm{d}}(\mathrm{m} / \mathbf{s})$ & $\mathrm{C}_{\mathrm{s}}(\mathrm{m} / \mathbf{s})$ & $\rho\left(\mathrm{kg} / \mathbf{m}^{3}\right)$ & $\mathrm{E}_{\mathrm{d}}(\mathrm{GPa})$ & $\mathrm{K}(\mathrm{GPa})$ & $\boldsymbol{v}_{\mathrm{d}}$ \\
\hline PMMA & 2382 & 1305 & 1187 & 5.61 & 4.35 & 0.28 \\
\hline
\end{tabular}

\subsection{Experiment Results and Discussion}

In the experiment, specimens with nine patterns, as listed in Table 2, were employed, and SHPB impact tests were conducted with a constant impact speed of $8.0 \mathrm{~m} / \mathrm{s}$. To avoid the contingency factor being disturbed by random error, the data were filtered carefully based on the processing principle, and then analyzed. With the signal from strain gauges on the incident and transmitted bar, the loading curves of the bars could be obtained and modified utilizing Origin software, as shown in Figure 4. Despite the stress equilibrium in the bars, the dynamic force equilibrium was not satisfied in the specimens. It is acknowledged that the dynamic force equilibrium is critical in SHPB experiments, and the basic assumption of a quasi-static method where the stress/strain of specimen is uniformly distributed was pointed out for the purpose of decoupling the stress wave effect and strain rate effect. However, the present paper focused on crack propagation and the holes' effect with a numerical investigation, which is already beyond the scope of a quasi-static study. A hybrid experimental-numerical approach [27] was employed without assumption of the stress balance required. 


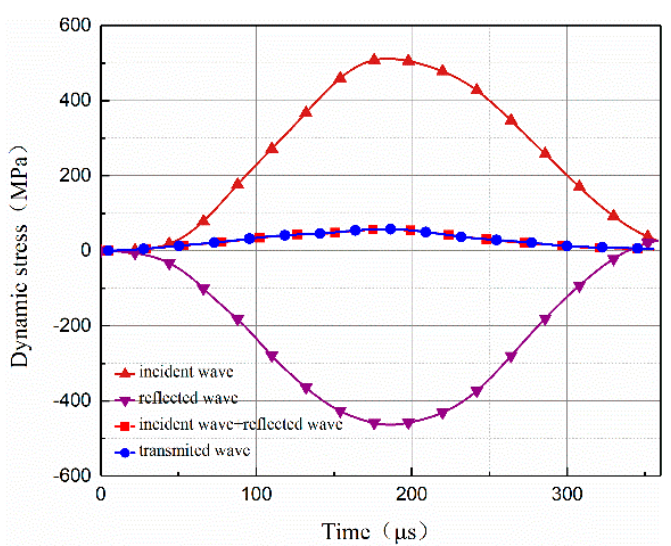

(a)

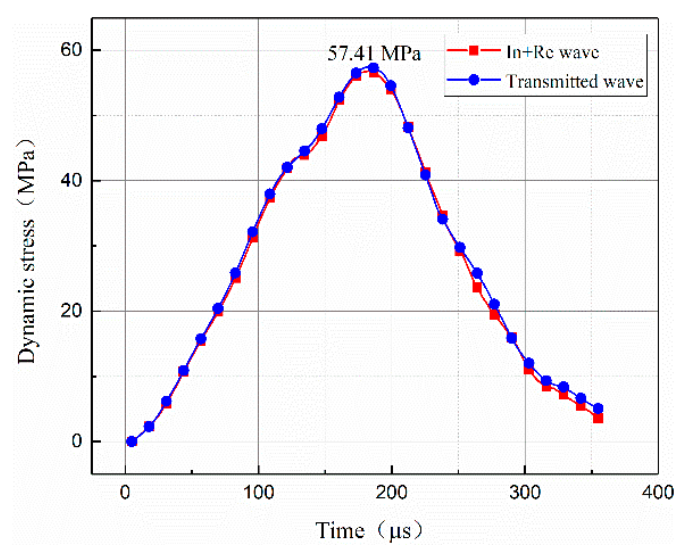

(b)

Figure 4. Dynamic stress curves. (a) Dynamic stress curves of the incident bar and transmitted bar. (b) Dynamic stress curves in the experiment.

The nine types of crack fracture patterns are illustrated in Figure 5, according to the distances $\mathrm{B}$ and $\mathrm{D}$ in Table 2. It is evident that the main cracks in all the specimens propagated straight after initiation as a mode I crack. For the B12-D15 and B12-D30 specimens, the cracks were arrested in the holes' zones and two new branching cracks connected with the holes, while the remaining specimens showed that the main cracks could penetrate the holes' zone, leaving a typical straight line and stopping in the rear part of the specimens.

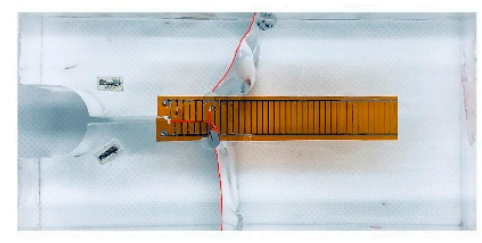

(a) $\mathrm{B} 12-\mathrm{D} 15$

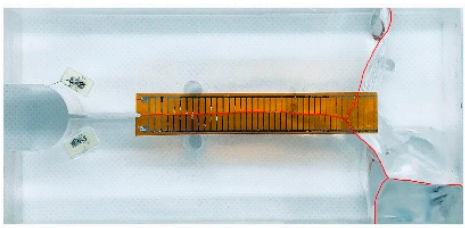

(d) B16-D15

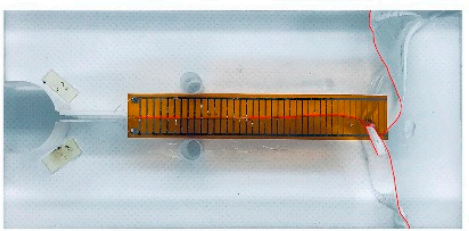

(g) B20-D15

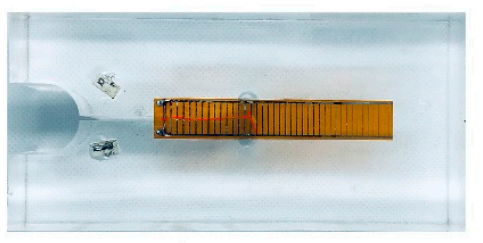

(b) B12-D30

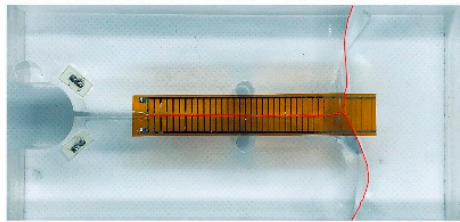

(e) B16-D30

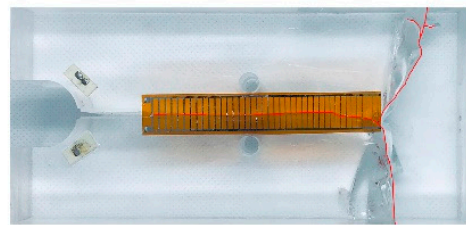

(h) B20-D30

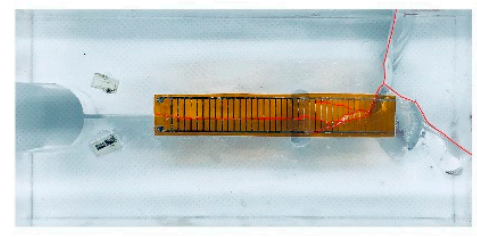

(c) B12-D45

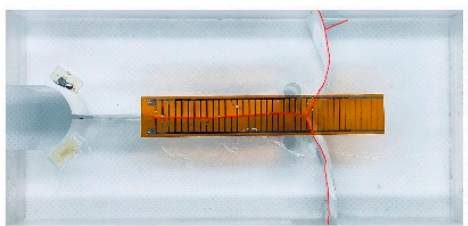

(f) B16-D45

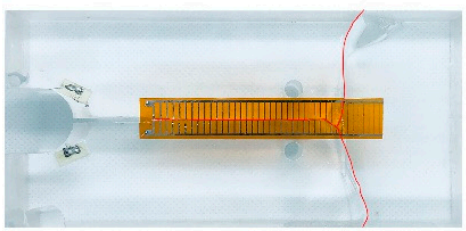

(i) $1320-\mathrm{D} 45$

Figure 5. Crack fracture patterns of the specimens. (a) Crack pattern of the B12-D15 specimen. (b) Crack pattern of the B12-D30 specimen. (c) Crack pattern of the B12-D45 specimen. (d) Crack pattern of the B16-D15 specimen. (e) Crack pattern of the B16-D30 specimen. (f) Crack pattern of the B16-D45 specimen. (g) Crack pattern of the B20-D15 specimen. (h) Crack pattern of the B20-D30 specimen. (i) Crack pattern of the B20-D45 specimen.

It is noteworthy that the transverse cracks in the rear of the specimens might be shaped by the secondary impact. To verify the influence of the secondary impact, examples are given, with crack propagation gauge (CPG) data and crack paths displayed in Figure 6. As mentioned above, the tightly glued CPG on the specimen could be employed to detect the crack propagation process as the wires 
on the CPG could be fractured by the running crack, resulting in regular voltage signal changes. In Figure $6 \mathrm{a}$, after the initial impact, the wires of the CPG were sequentially fractured by the running crack until the crack reached the 31st wire. This process took $397.6 \mu \mathrm{s}$, which is longer than the average impact stress wavelength, $360.1 \mu \mathrm{s}$, as shown in Figure 4. Meanwhile, the running crack stopped at the 31st wire, with the CPG voltage signal staying constant. However, the CPG voltage signal changed again after $642.6 \mu \mathrm{s}$, as the 32 nd wire was fractured by the restarted crack. Figure $6 \mathrm{~b}$ tells the same story. This phenomenon suggests that the secondary impact could offer energy to the stopped crack, making it restart. Moreover, the transverse crack paths in the rear of the specimens were induced by the secondary impact. This is because the crack paths were almost a straight line before the secondary impact occurred, as shown in Figure 6, when the action time was considered. During the secondary impact process, the bottom of the specimen restricted by the transmitted bar had a smaller deformation than the top where a large semi-circle hole existed. When the specimen underwent the secondary impact, the discordance of deformation restarted the already stopped crack and induced the transverse cracks.
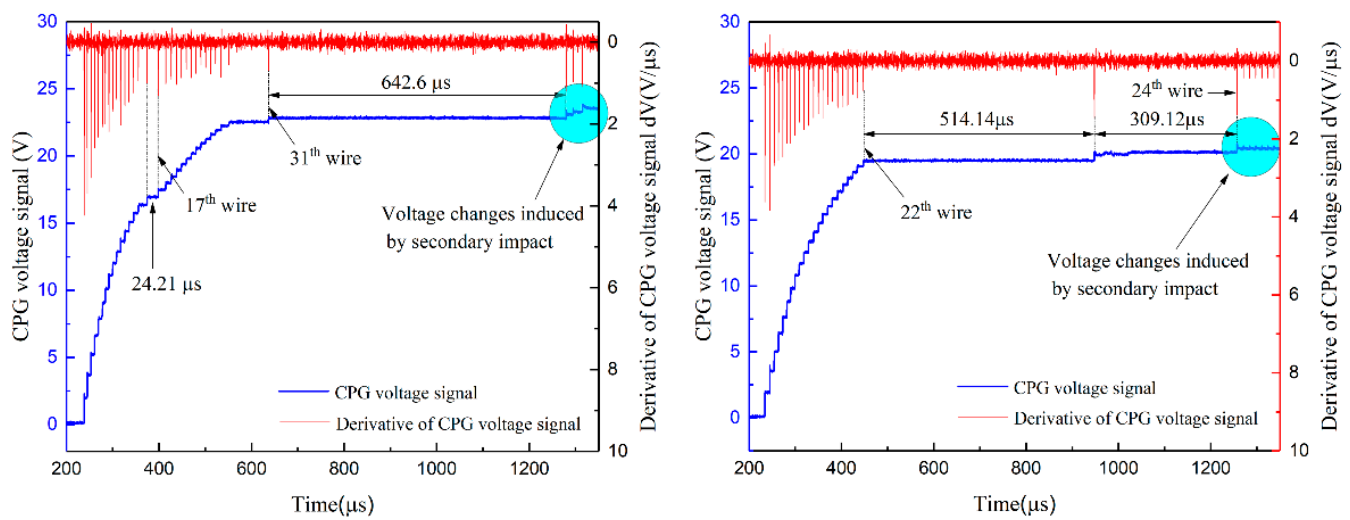

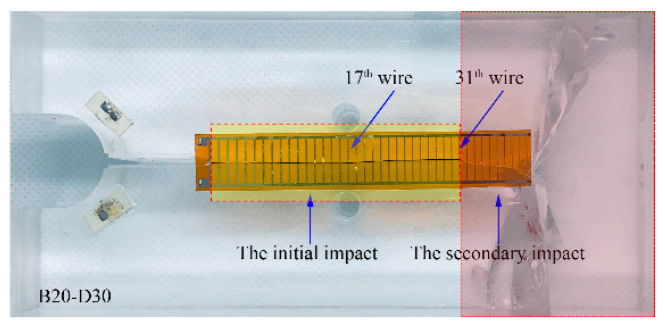

(a) B20-D30 specimen

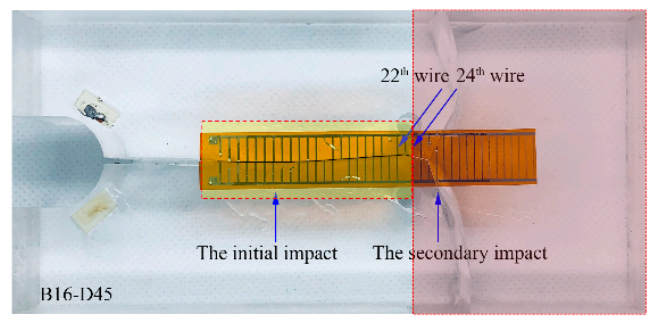

(b) B16-D45 specimen

Figure 6. The voltage signal curves of crack propagation gauges (CPGs) and the crack paths of the specimens. (a) B20-D30 specimen. (b) B16-D45 specimen.

Nevertheless, the influence of the secondary impact can be ignored, as the secondary impact basically occurred $1000 \mu$ s later after crack initiation, which means that the running crack already passed the holes' zone and finished the expected complete propagation process; furthermore, data collection was already completed before the secondary impact occurred.

Notably, it is distinct that the crack propagation behavior changed drastically in the holes' zone, with branching cracks appearing when the distance $(B=12 \mathrm{~mm})$ between the holes was small. The influence of the holes was very dependent on the distance $B$; as B increased to $16 \mathrm{~mm}$, those fracture phenomena disappeared. To better understand the influence of the holes on the propagating crack, the CPG data were taken into consideration and the crack propagating velocity was obtained using the distance of $2 \mathrm{~mm}$ divided by the fracture time of the adjacent wires. The results are demonstrated in Figure 7. 


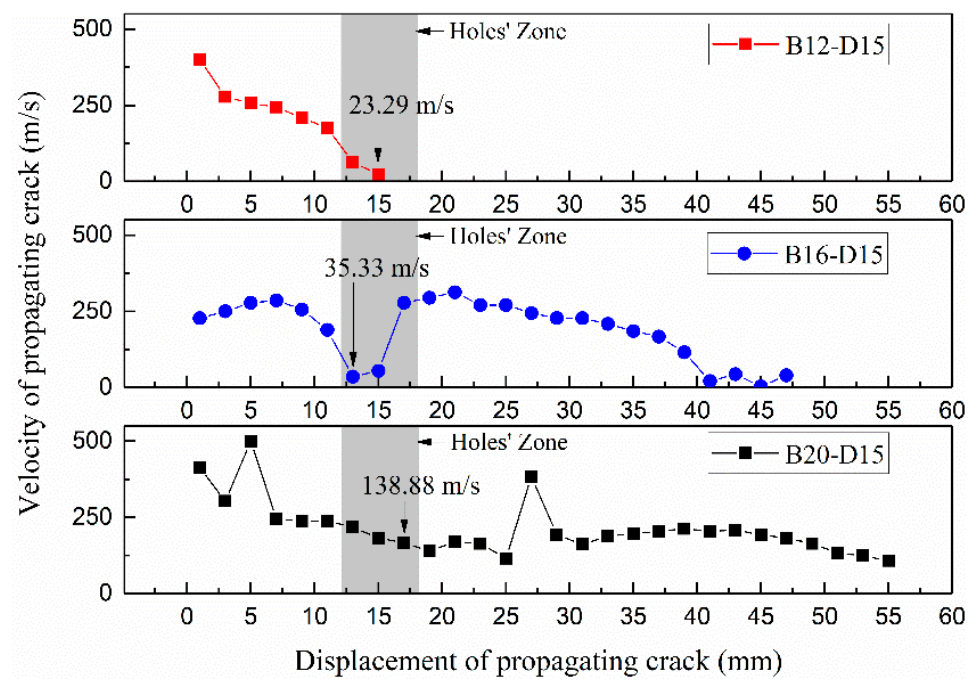

(a)

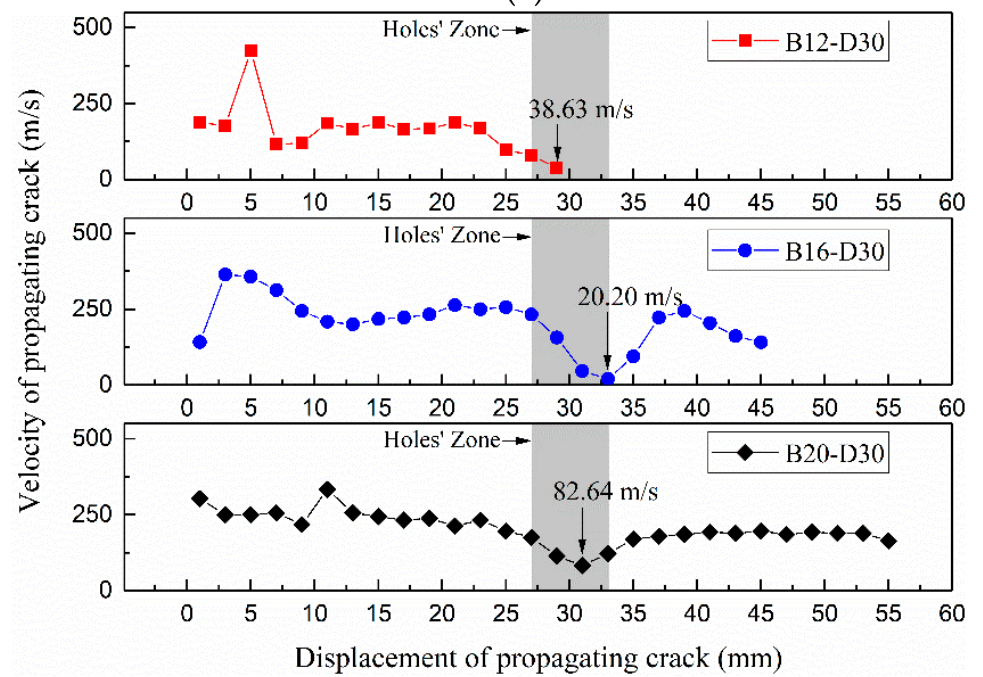

(b)

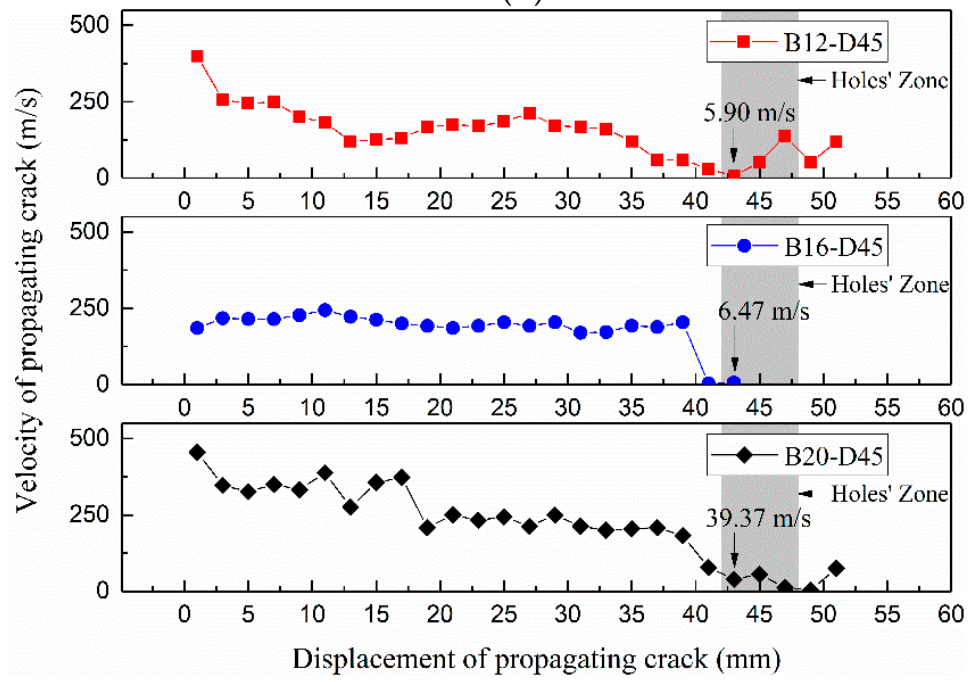

(c)

Figure 7. Crack propagation velocity curves of different types of specimen. (a) Specimen with constant $\mathrm{D}=15 \mathrm{~mm}$. (b) Specimen with constant $\mathrm{D}=30 \mathrm{~mm}$. (c) Specimen with constant $\mathrm{D}=45 \mathrm{~mm}$. 
The velocity curves show when the distance $D$ between the centers of the holes and the crack tip was constant at $15 \mathrm{~mm}$, whereas the holes with distance $B=12 \mathrm{~mm}$ could fully arrest the running crack and potentially induce branching cracks connecting the two holes. When distance B was $16 \mathrm{~mm}$, the holes could transitorily arrest the crack with a very low speed of $35.33 \mathrm{~m} / \mathrm{s}$, but no branching cracks emerged. When distance B was $20 \mathrm{~mm}$, the two holes had a very limited effect on the crack path with a speed of $138.88 \mathrm{~m} / \mathrm{s}$, and its velocity curves changed inconspicuously. This indicates that the holes had a suppressing action on the moving crack as the two-hole spacing decreased.

As distance D changed from $15 \mathrm{~mm}$ to $45 \mathrm{~mm}$, the velocity between the holes became smaller; for example, the minimum propagation speeds between holes in B12-D35 and B16-D35 were 35.33 $\mathrm{m} / \mathrm{s}$ and $20.20 \mathrm{~m} / \mathrm{s}$. However, the deceleration tendency was controlled by distance B. This suggests that the arrest function of the extending crack would be intensified by the enlargement of distance $D$. Nevertheless, the fact that the propagation speed became very small when $\mathrm{D}=45 \mathrm{~mm}$ should be noted, as it was not only contributed by the holes' effect but also by the decrease in impact energy release.

The crucial data of crack propagation are listed in Table 4 . The data demonstrate that the effect of the empty holes on the propagation crack had a sensitive relationship with distance $B$ and $D$. As distance $B$ decreased, the propagation velocity decreased. When distance $D$ increased, the holes' influence was magnified. For a deep understanding, a finite difference code was introduced to investigate the mechanism of the holes' effect and crack propagation behaviors.

Table 4. Crucial data of crack propagation.

\begin{tabular}{cccccccccccc}
\hline Specimen & $\begin{array}{c}\mathrm{AT} \\
\mu \mathrm{s}\end{array}$ & $\begin{array}{c}\mathbf{V}_{\min } \\
\mathrm{m} / \mathrm{s}\end{array}$ & $\begin{array}{c}\mathbf{V}_{\text {avg }} \\
\mathrm{m} / \mathrm{s}\end{array}$ & specimen & $\begin{array}{c}\mathrm{AT} \\
\mu \mathrm{s}\end{array}$ & $\begin{array}{c}\mathbf{V}_{\min } \\
\mathrm{m} / \mathrm{s}\end{array}$ & $\begin{array}{c}\mathbf{V}_{\text {avg }} \\
\mathrm{m} / \mathrm{s}\end{array}$ & Specimen & $\begin{array}{c}\mathrm{AT} \\
\mu \mathrm{s}\end{array}$ & $\begin{array}{c}\mathbf{V}_{\min } \\
\mathrm{m} / \mathrm{s}\end{array}$ & $\begin{array}{c}\mathbf{V}_{\text {avg }} \\
\mathrm{m} / \mathrm{s}\end{array}$ \\
\hline B12-D15 & 85.87 & 23.29 & 205.95 & B12-D30 & 51.77 & 38.63 & 164.46 & B12-D45 & 338.98 & 5.90 & 152.82 \\
B16-D15 & 56.60 & 35.33 & 186.69 & B16-D30 & 99.90 & 20.02 & 208.30 & B16-D45 & 309.11 & 6.47 & 183.93 \\
B20-D15 & 14.40 & 138.88 & 212.32 & B20-D30 & 24.20 & 82.64 & 205.18 & B20-D45 & 50.80 & 39.37 & 225.88 \\
\hline
\end{tabular}

In this table, $A T$ is short for arrest time, $V_{\min }$ is minimum velocity, and $V_{\text {avg }}$ is average velocity.

\section{Numerical Method}

To solve multifarious problems involving deformation and fracture failure in brittle material such as concrete, rock, and polymethyl methacrylate, a finite difference code named AUTODYN can be applied.

\subsection{Introduction of the Algorithm in AUTODYN}

To illustrate the algorithm of AUTODYN [16,17], a group of elements undergoing dynamic loading and their potential deformation are presented in Figure 8. The material parameters were ascribed to all elements with the same value. When subjected to dynamic loading, the nodes of the elements move with independent velocity, causing deformation.
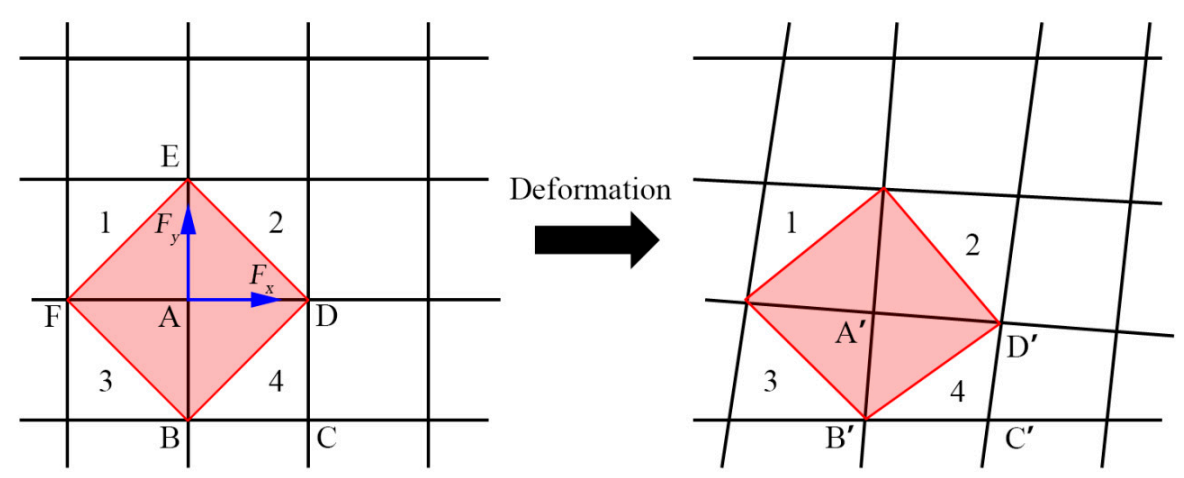

Figure 8. Elements and potential deformation under dynamic loading. 
The acceleration of node A in Figure 8 can be expressed by Equation (5), according to Newton's law.

$$
\begin{aligned}
& F_{x}=m \cdot \ddot{u} \\
& F_{y}=m \cdot \ddot{v}
\end{aligned}
$$

where $\ddot{u}$ and $\ddot{v}$ are the accelerations in $x$ - and $y$-directions, respectively, $m$ is mass, and $F_{x}$ and $F_{y}$ are the forces in $x$ - and $y$-directions. respectively. Then, the velocity $\dot{u}$ and $\dot{v}$ of node $\mathrm{A}$ with time in $x$-and $y$-directions can be determined using Equation (6).

$$
\begin{aligned}
& \dot{u}_{n+1}=\dot{u}_{n}+\ddot{u}_{n} \Delta t \\
& \dot{v}_{n+1}=\dot{v}_{n}+\ddot{v}_{n} \Delta t
\end{aligned},
$$

where $n$ is the time step and $\Delta t$ is the time increment. The strain rates of elements (surrounded by A, B, $C$, and D nodes) are calculated using Equation (7).

$$
\begin{aligned}
& \dot{\varepsilon}_{x}=\frac{\partial \dot{u}}{\partial x}=\frac{1}{2 A^{n+\frac{1}{2}}}\left[\left(\dot{u}_{A}-\dot{u}_{c}\right)\left(y_{B}-y_{D}\right)-\left(\dot{u}_{B}-\dot{u}_{D}\right)\left(y_{A}-y_{C}\right)\right] \\
& \left.\dot{\varepsilon}_{y}=\frac{\partial \dot{v}}{\partial y}=\frac{1}{2 A^{n+\frac{1}{2}}}\left[\dot{v}_{A}-\dot{v}_{C}\right)\left(x_{B}-x_{D}\right)-\left(\dot{v}_{B}-\dot{v}_{D}\right)\left(x_{A}-x_{C}\right)\right] \\
& \dot{\gamma}_{x y}=\frac{\partial \dot{v}}{\partial x}+\frac{\partial u}{\partial y}=\frac{1}{2 A^{n+\frac{1}{2}}}\left[\left(\dot{v}_{A}-\dot{v}_{C}\right)\left(y_{B}-y_{D}\right)-\left(\dot{v}_{B}-\dot{v}_{D}\right)\left(y_{A}-y_{C}\right)\right. \\
& \left.+\left(\dot{u}_{A}-\dot{u}_{c}\right)\left(x_{B}-x_{D}\right)-\left(\dot{u}_{B}-\dot{u}_{D}\right)\left(x_{A}-x_{C}\right)\right]
\end{aligned},
$$

where $\dot{\varepsilon}_{x}$ and $\dot{\varepsilon}_{y}$ are the strain rates of the element $\mathrm{ABCD}$ in $x$ - and $y$-directions, respectively, whereas $\dot{\gamma}_{x y}$ is the strain rate of element ABCD in the $x y$ plane. Then, the stress deviators can be calculated using Equation (8),

$$
\begin{aligned}
& S_{x}^{n+1}=S_{x}^{n}+2 G\left(\dot{\varepsilon}_{x}-\frac{1}{3} e\right)^{n+\frac{1}{2}} \Delta t \\
& S_{y}^{n+1}=S_{y}^{n}+2 G\left(\dot{\varepsilon}_{y}-\frac{1}{3} e\right)^{n+\frac{1}{2}} \Delta t \\
& S_{x y}^{n+1}=S_{x y}^{n}+2 G \dot{\varepsilon}_{x y}{ }^{n+\frac{1}{2}} \Delta t
\end{aligned}
$$

where $S$ is the stress deviator, $G$ is the shear modulus, and $\dot{e}$ is the volume strain. Therefore, the dynamic stress can be expressed as shown in Equation (9).

$$
\begin{aligned}
& \sigma_{x}=P+S_{x} \\
& \sigma_{y}=P+S_{y} \\
& \tau_{x y}=S_{x y}
\end{aligned}
$$

where the pressure determined by the equation of state (EOS) is $P$, and the linear EOS was chosen in the numerical simulation with an advantage in investigating typical brittle materials, as shown in Equation (10).

$$
P=\kappa \cdot\left(\frac{\rho}{\rho_{0}}-1\right),
$$

where $P$ is the pressure, $\kappa$ is the bulk modulus, $\rho$ is the current density of the rock, and $\rho_{0}$ is the initial density of the rock.

Here, the classic wave propagation equations are introduced below.

$$
\begin{aligned}
& \frac{\partial \sigma_{x}}{\partial x}+\frac{\partial \tau_{x y}}{\partial y}=\rho \frac{\partial^{2} u}{\partial t^{2}} \\
& \frac{\partial \sigma_{y}}{\partial y}+\frac{\partial \tau_{x y}}{\partial x}=\rho \frac{\partial^{2} v}{\partial t^{2}}
\end{aligned} .
$$


Ultimately, based on Green's formula, Equation (11) can be rewritten as Equation (12).

$$
\begin{aligned}
& \int_{L}\left[\sigma_{x} d y-\tau_{x y} d x\right]=\iint_{D} \rho \frac{\partial^{2} u}{\partial t^{2}} d x d y=2 F_{x} \\
& \int_{L}\left[\tau_{x y} d y-\sigma_{x} d x\right]=\iint_{D} \rho \frac{\partial^{2} v}{\partial t^{2}} d x d y=2 F_{y}{ }^{\prime}
\end{aligned}
$$

where the domain of integration $D$ is the red area in Figure 8, while $L$ is its contour. Therefore, with Equation (12), one can obtain the finite different Equation (13).

$$
\begin{gathered}
F_{x}=\frac{1}{2}\left[\sigma_{x}{ }^{1}\left(y_{F}-y_{E}\right)-\tau_{x y}{ }^{1}\left(x_{F}-x_{E}\right)+\sigma_{x}{ }^{2}\left(y_{B}-y_{F}\right)-\tau_{x y}{ }^{2}\left(x_{B}-x_{F}\right)\right. \\
\left.+\sigma_{x}{ }^{3}\left(y_{D}-y_{B}\right)-\tau_{x y}{ }^{3}\left(x_{D}-x_{B}\right)+\sigma_{x}{ }^{4}\left(y_{E}-y_{D}\right)-\tau_{x y}{ }^{4}\left(x_{E}-x_{D}\right)\right] \\
F_{y}=\frac{1}{2}\left[\tau_{x y}{ }^{1}\left(y_{F}-y_{E}\right)-\sigma_{y}{ }^{1}\left(x_{F}-x_{E}\right)+\tau_{x y}{ }^{2}\left(y_{B}-y_{F}\right)-\sigma_{y}{ }^{2}\left(x_{B}-x_{F}\right)\right. \\
\left.+\tau_{x y}{ }^{3}\left(y_{D}-y_{B}\right)-\sigma_{y}{ }^{3}\left(x_{D}-x_{B}\right)+\tau_{x y}{ }^{4}\left(y_{E}-y_{D}\right)-\sigma_{y}{ }^{4}\left(x_{E}-x_{D}\right)\right]
\end{gathered}
$$

where 1,2,3, and 4 are the serial numbers of the elements in Figure 8, respectively.

\subsection{Numerical Damage Mode}

In the numerical simulation, the linear equation of state was employed to express the brittle material state. The principal stress criterion was selected as the fundamental rule as the fracture of the specimens was a typical mode I crack. In addition, the softening damage criterion was also implemented during the calculation. When the gradual process of crack propagation was taken into consideration, in which crack developed from the micro-cracks and generated the main crack, the softening damage mode it was involved, as shown in Figure 9.
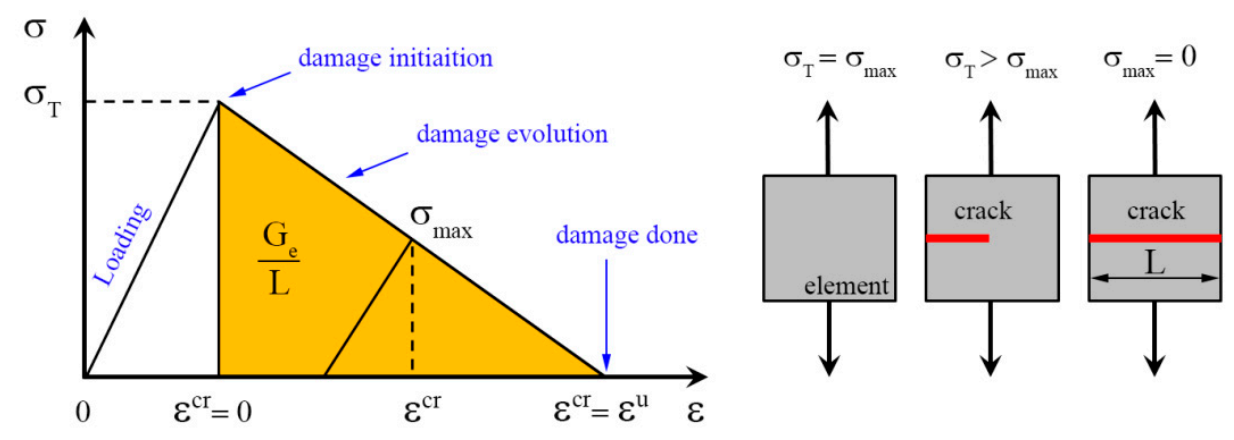

Figure 9. Schematic of softening damage criterion.

The whole strain-stress curve can be divided into two stages, each dominated by different damage states. In the loading part, the potential fracture element begins with zero tensile strength. When the element undergoes loading, its elastic strain keeps increasing until the maximum principal stress reaches the maximum dynamic tensile strength $\sigma_{T}$. Then, the element is damaged with crack strain $\varepsilon^{c r}$ increasing, which is called the damage evolution process. In this damaging stage, a damage factor $D^{d a m}$ is defined to model the consecutive fracture. For intact elements, $D^{\text {dam }}$ is 0 , and, for fully fractured elements, $D^{d a m}$ is 1 . In addition, when the damage is done, the total fracture strain is $\varepsilon^{u}$. Therefore, $D^{d a m}$ is a function of $\varepsilon^{c r}$ and $\varepsilon^{u}$, which can be expressed by Equation (14).

$$
\begin{aligned}
& \varepsilon^{u}=2 \frac{G_{e}}{\sigma_{T} L} \\
& D^{d a m}=\frac{\varepsilon^{c r}}{\varepsilon^{u}}=\frac{\varepsilon^{c r} \sigma_{T} L}{2 G_{e}}, \\
& \sigma_{\max }=\sigma_{T}\left(1-D^{\text {dam }}\right)
\end{aligned}
$$

where $D^{d a m}$ is the damage factor, $\varepsilon^{c r}$ is the fracture strain, $\varepsilon^{u}$ is the total fracture strain, $\sigma_{T}$ is the maximum dynamic tensile strength, $L$ is the characteristic dimension in the direction of maximum principal stress of the element, $G_{e}$ is the fracture energy, and $\sigma_{\max }$ is the bearing maximum principal 
stress. In addition, the bearing maximum principle stress keeps decreasing to zero. The fractured element can still maintain its capacity to withstand compression and shear loads but not tensile loads.

The practical geometry dimension in Figure 1 was applied in establishing the numerical model of the specimens. Based on the principle of the experimental-numerical method, the material parameters in Table 3 were loaded, as well as the stress-time data from the experiment shown in Figure 4. In order to acquire precise calculation with efficient computational power, the mesh of the specimens was well designed, as shown in Figure 10. Elements with length of $0.1 \mathrm{~mm} \times 0.1 \mathrm{~mm}$ were deployed along the crack tip covering the area where possible crack propagation could happen. The holes' area was specifically meshed with relatively fine grids generated around the holes to avoid mesh distortion. Meanwhile, the gauges were placed along the axis of the specimen with a constant distance of $2.0 \mathrm{~mm}$ acting as the CPG in the experiment.

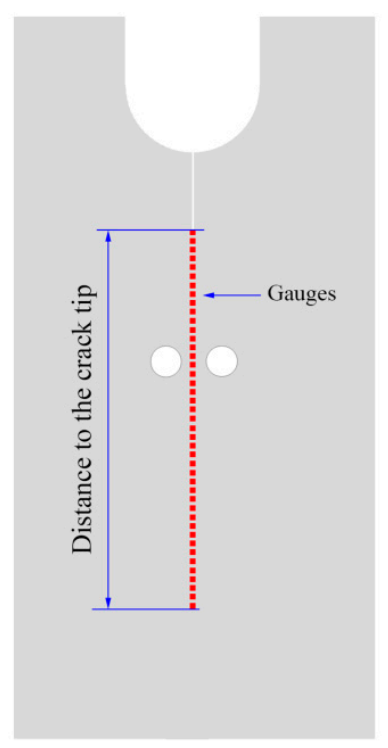

(a)

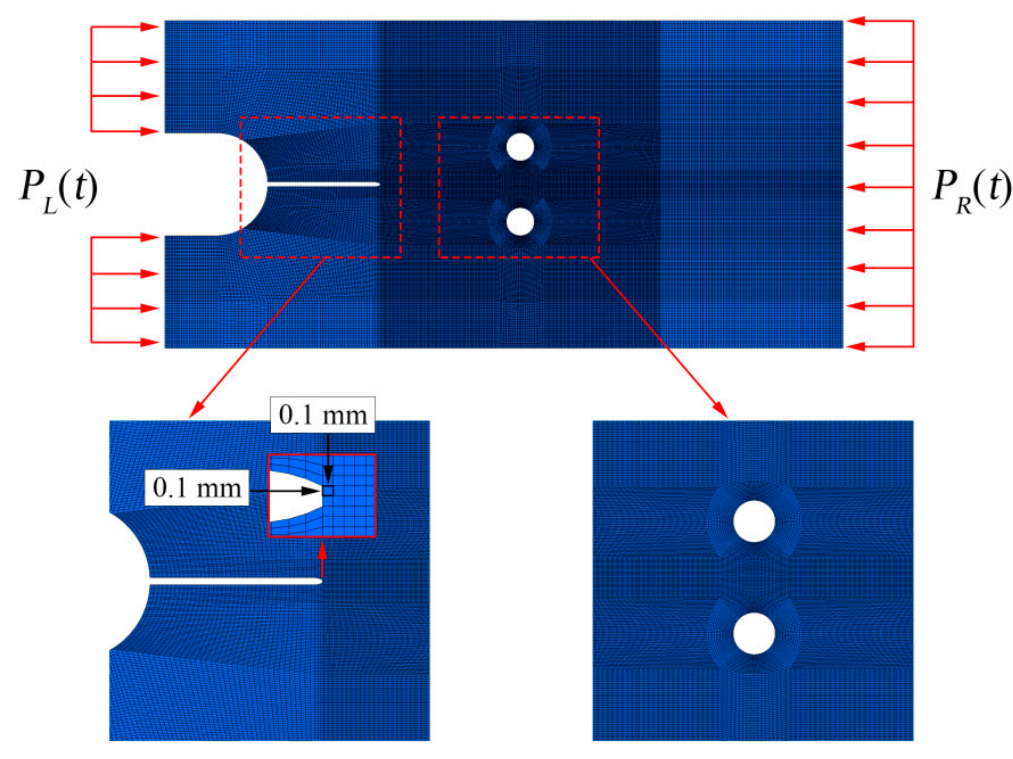

(b)

Figure 10. Numerical (AUTODYN) simulation specimen. (a) Location of gauge points on the specimen. (b) Mesh of the specimen.

\subsection{Numerical Simulation Results}

The crack propagation patterns calculated using the numerical simulation are illustrated in Figure 11. The numerical simulation results agree well with the experiments, as the crack paths present a universal appearance with a straight line after initiation, while branching cracks occurred in the holes' zone in the B12-D15 and B12-30 specimens, as observed in the actual experiment. However, it is hard to identify the transverse cracks in the specimens. As mentioned, the transverse cracks in the experiment were induced by secondary impact, but there was no chance for secondary impact in this numerical simulation, as a single full period of dynamic loading was applied in the simulation. 


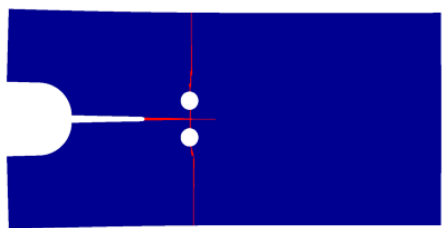

(a) B12-D15

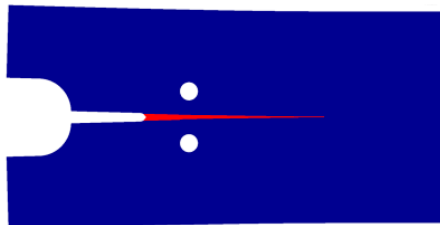

(d) B16-D15

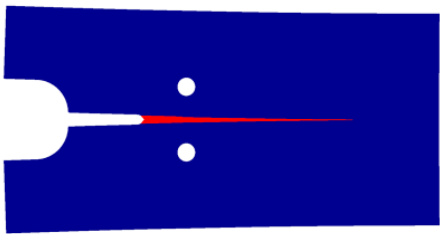

(g) B20-D15

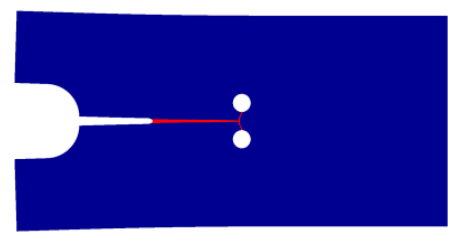

(b) B12-D30

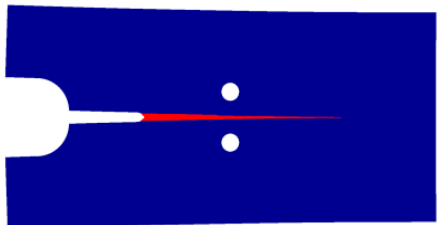

(e) B16-D30

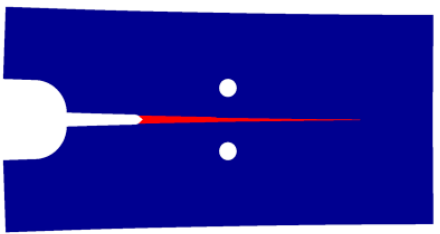

(h) B20-D30

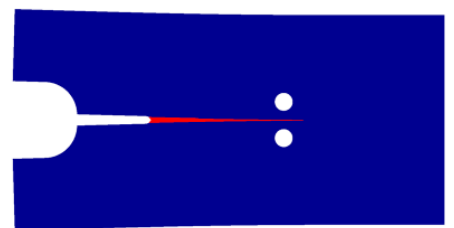

(c) B12-D45

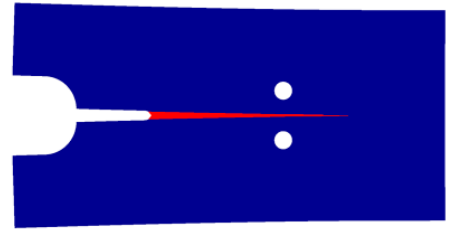

(f) B16-D45

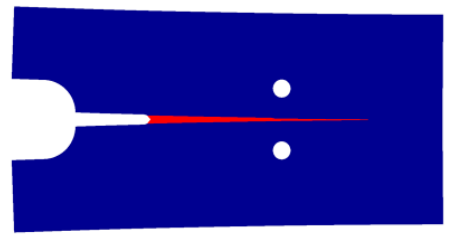

(i) B20-D45

Figure 11. Numerical (AUTODYN) results of crack propagation paths.

Therefore, the reliability of the numerical simulation could be verified, and numerical analysis was conducted to investigate the holes' effect on crack propagation. The fractured time of each gauge point in the simulation was detected and stored as data; using these data, the crack propagating velocity could be obtained. Thus, the crack propagation velocity curves collected from numerical simulation are illustrated in Figure 12, together with the experimental results as a comparison.

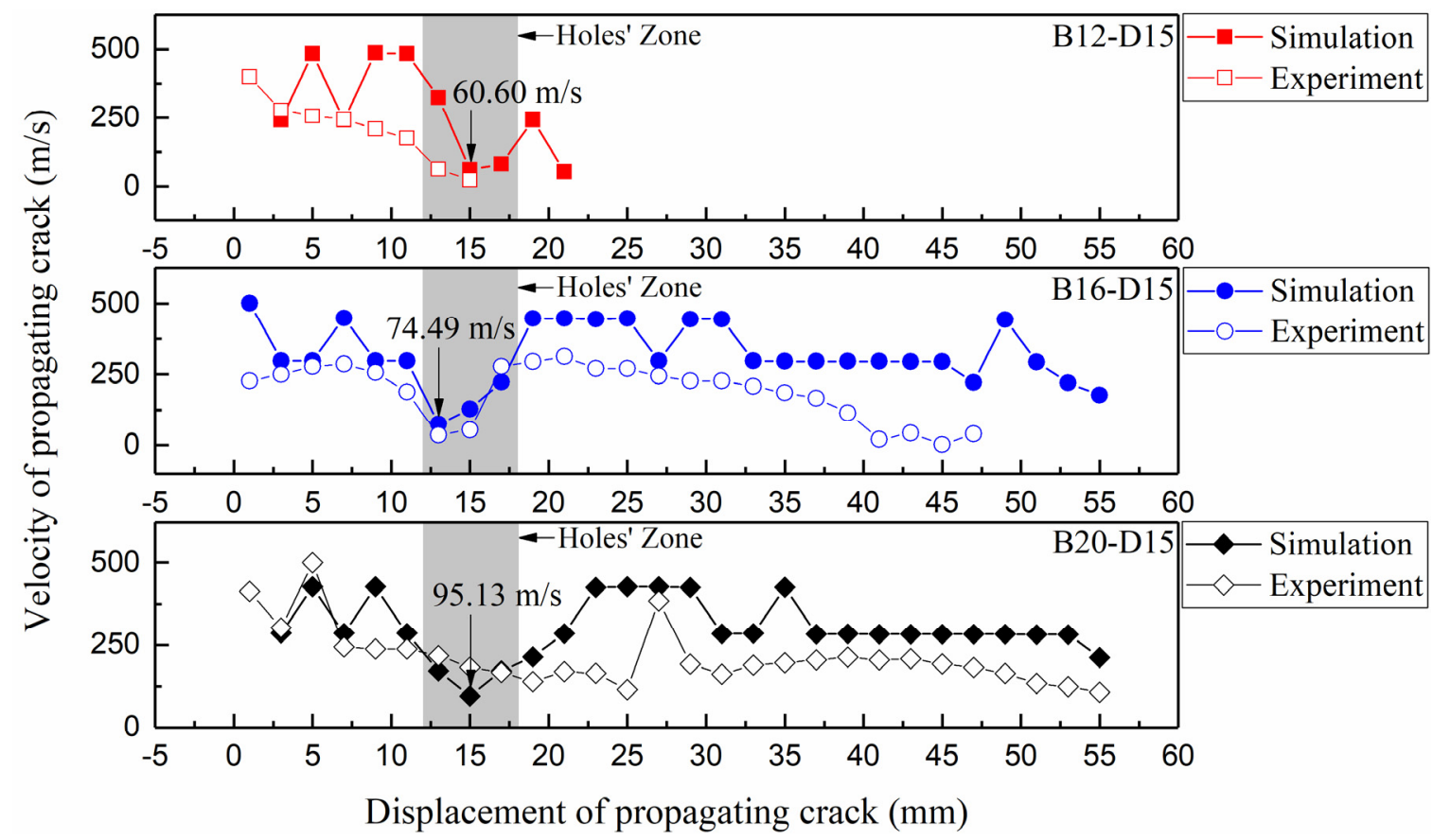

(a)

Figure 12. Cont. 


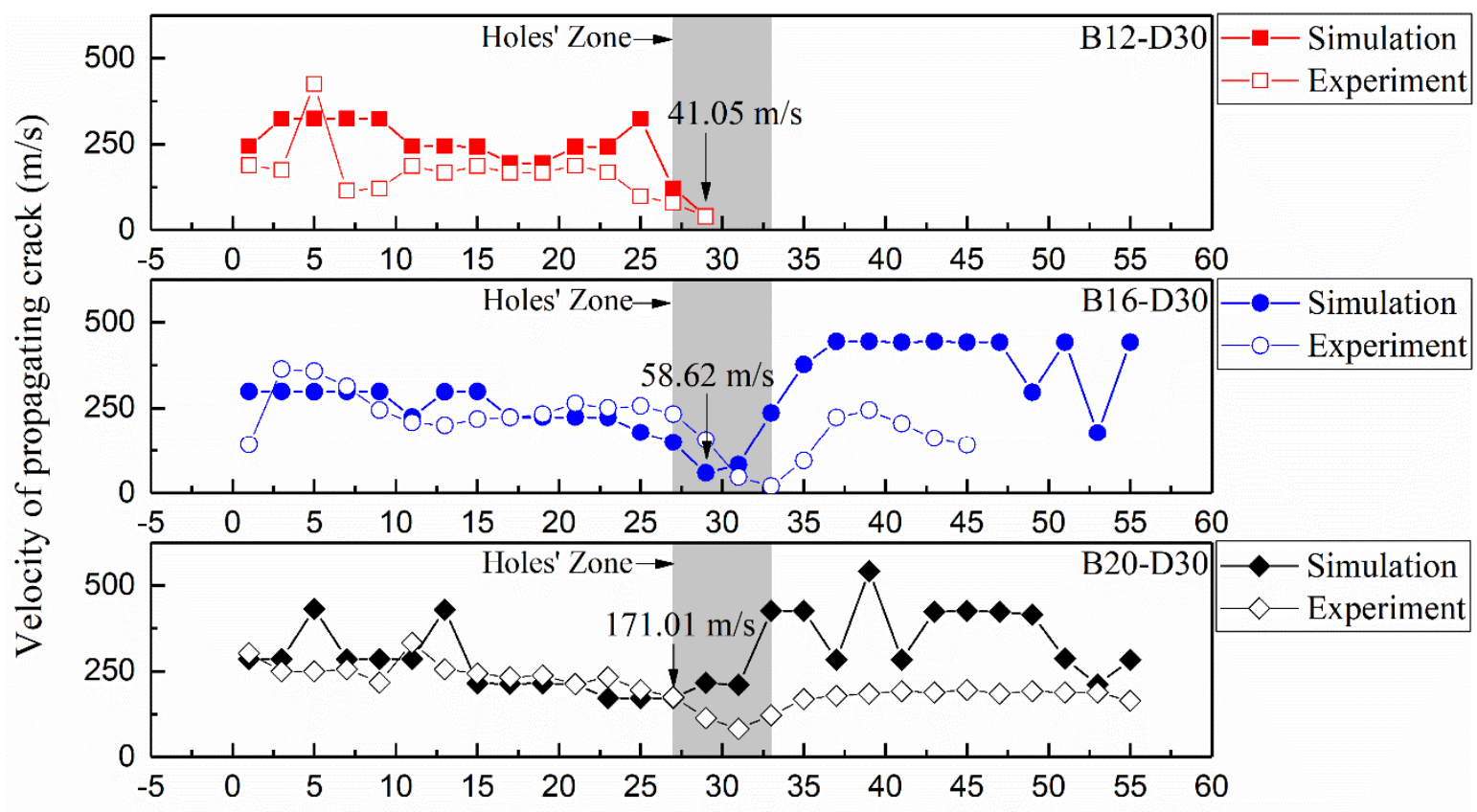

Displacement of propagating crack $(\mathrm{mm})$

(b)

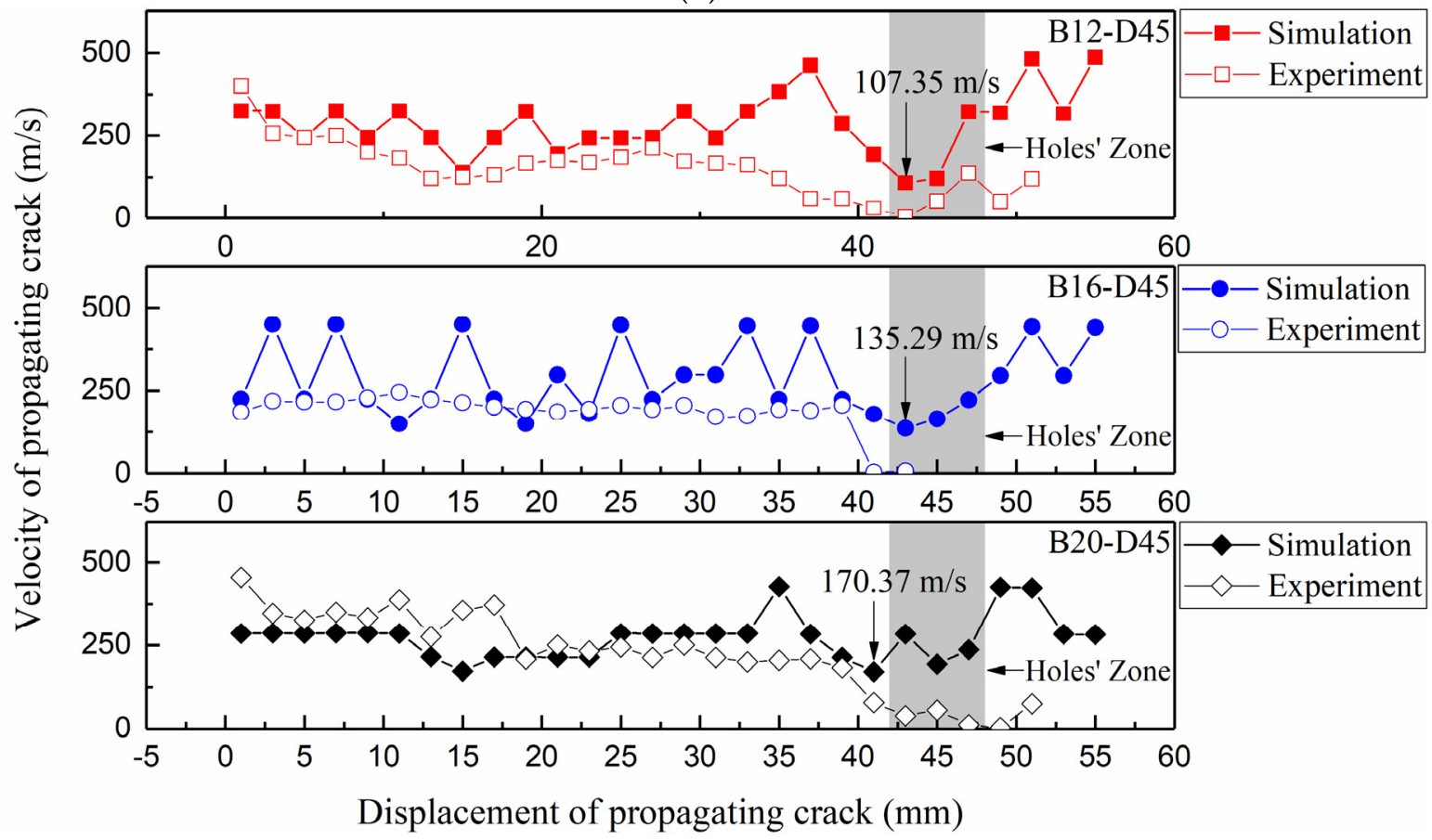

(c)

Figure 12. Crack propagation velocity curves of different types of specimens using AUTODYN. (a) Specimen with constant D = $15 \mathrm{~mm}$. (b) Specimen with constant D = $30 \mathrm{~mm}$. (c) Specimen with constant $\mathrm{D}=45 \mathrm{~mm}$.

It is distinct that the holes' effect on crack propagation behavior was remarkable and dependent on the distance B and D, which means that, when B and D changed, so did the influence of the holes. The crack propagating velocity was sharply reduced when the crack approached the holes, which could be used to determine the strength of the holes' function. For holes with constant $\mathrm{D}=15 \mathrm{~mm}$, the decay rates of the crack propagating velocity were different, with a smaller distance between the holes resulting in a stronger influence. These influences were magnified when distance $\mathrm{D}$ was increased 
from $15 \mathrm{~mm}$ to $30 \mathrm{~mm}$ due to the decrease in impact energy released by the crack. Additionally, the fracture performances differed as distance $B$ changed. When holes had $B=12$, the branching cracks connected with the holes, stopping the crack in the holes' zone. On the other hand, when holes had $\mathrm{B}=16$, the holes could only transitorily restrain the extending crack, after which the crack regained its high speed, as shown in Figure 12b, with no branched cracks appearing.

\subsection{Discussion of Mechanism}

To discuss the holes' effect on the propagating crack, the specimen named B16-D30 was focused on, and its velocity vector contour is plotted in Figure 13.

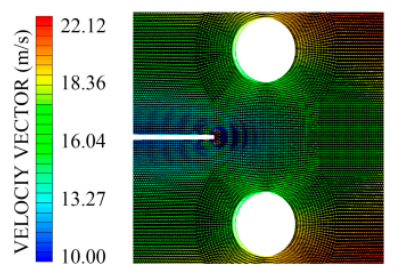

$\mathrm{t}=281.3 \mu \mathrm{s}$

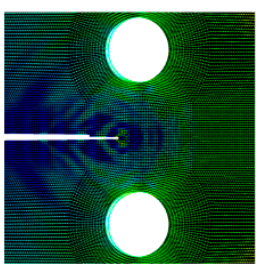

$t=290.6 \mu s$

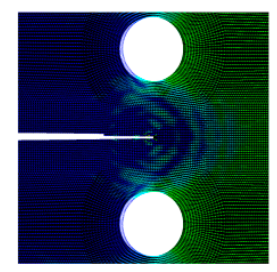

$\mathrm{t}=327.6 \mu \mathrm{s}$

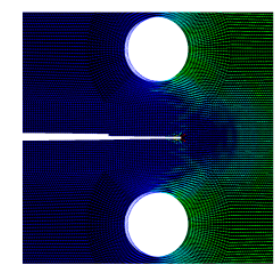

$\mathrm{t}=365.8 \mu \mathrm{s}$

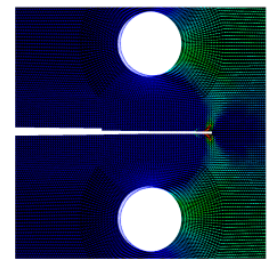

$\mathrm{t}=375.2 \mu \mathrm{s}$

(a)

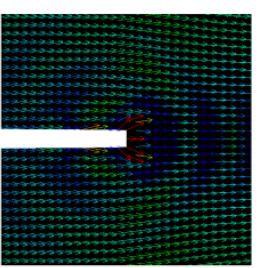

$\mathrm{t}=281.3 \mu \mathrm{s}$

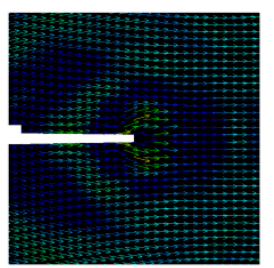

$\mathrm{t}=290.6 \mu \mathrm{s}$

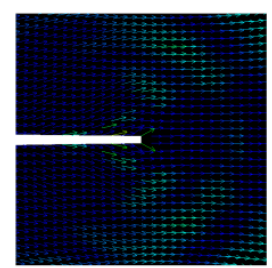

$\mathrm{t}=327.6 \mu \mathrm{s}$

(b)

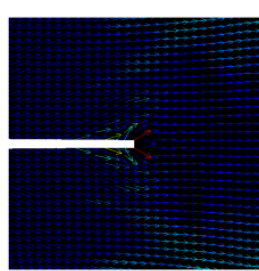

$\mathrm{t}=365.8 \mu \mathrm{s}$

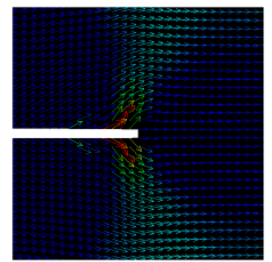

$\mathrm{t}=375.2 \mu \mathrm{s}$

Figure 13. Numerical (ATUODYN) results of the B16-D30 specimen. (a) Velocity vector contour in the central zone of the connection line between two holes. (b) Particle velocity vector on the crack tips.

During the stress wave propagation in the specimen, the particles were motivated by the stress wave with varying velocity. When the stress wave encountered the surfaces of the holes, the particles on the free surface were without constraint and moved forward, which caused deformation of the holes. Together with the extending of the crack tip, the velocity of the particles between the holes and crack tip changed in terms of both magnitude and direction. Thus, the state motion of the particles in the crack tip was influenced and the crack propagation behavior responded. From Figure 13b, it can be observed that the particles in the running crack tip were restrained when the crack rushed into the holes' zone, lasting until the crack escaped the zone. This could explain the velocity curve in Figure $12 b$, where the crack propagating velocity firstly decreased in the holes' zone then increased.

The contour plots of maximum principal stress and compressive stress are illustrated in Figure 14. Figure 14a clearly shows that a compression area was formed between the two holes. In particular, in Figure $14 \mathrm{~b}$, the stress $\sigma_{\mathrm{yy}}$ was obtained by numerical simulation, in which " + " denotes compressive stress and " - " denotes tensile stress. When $t=288.3 \mu \mathrm{s}$, a compressive stress field already existed between the holes before the crack initiation with typical features. When $t=261.5 \mu$ s, the propagating crack approached the holes' zone, whereas the particles between the crack tip and the holes encountered each other, thereby reshaping the whole compressive field. When the crack tip in the central zone of the connection line was between two holes, the overlay effect of the stress field was more prominent, and this was also the specific time at which the crack arrest phenomenon occurred. Therefore, the effect of the holes was dependent on the compressive stress field caused by the particle movement during the crack propagation process. 


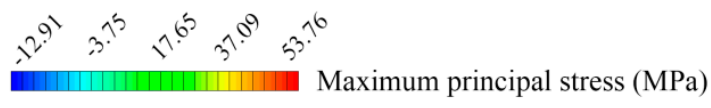

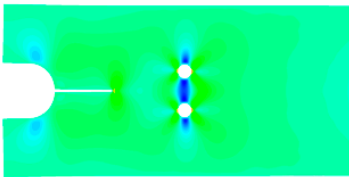

$\mathrm{t}=228.3 \mu \mathrm{s}$

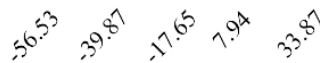

Compressive stress $\sigma_{y y}(\mathrm{MPa})$

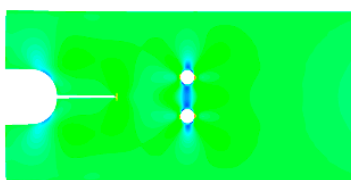

$\mathrm{t}=228.3 \mu \mathrm{s}$

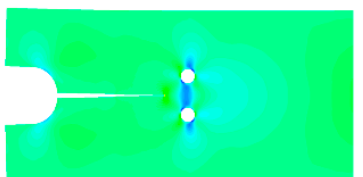

$\mathrm{t}=261.5 \mu \mathrm{s}$

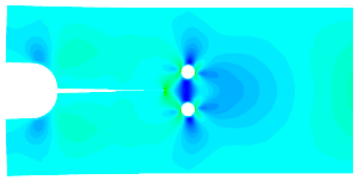

$\mathrm{t}=261.5 \mu \mathrm{s}$

(a)

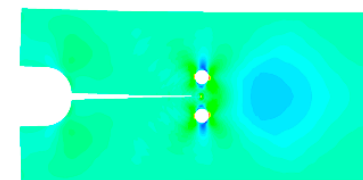

$\mathrm{t}=327.6 \mu \mathrm{s}$

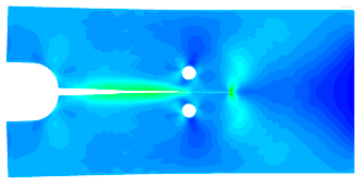

$\mathrm{t}=375.2 \mu \mathrm{s}$

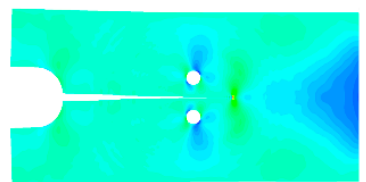

$\mathrm{t}=375.2 \mu \mathrm{s}$

(b)

Figure 14. Numerical (AUTODYN) results of B16-D30 specimen. (a) Contour plot of the maximum principal stress. (b) Contour plot of the compressive stress $\sigma_{\mathrm{yy}}$.

To quantitatively reveal the relationship between the holes' effect and the compressive stress field, the maximum compressive stress curves with different distance B and D are illustrated in Figure 15. The maximum compressive stress in the holes' zone was larger than that in other areas, except for the pre-crack tip. An extreme value appeared in the central zone of the connection line between the two holes, with values of 24.12 $\mathrm{MPa}, 28.64 \mathrm{MPa}$, and 27.27 $\mathrm{MPa}$ for the specimens with constant distance $\mathrm{B}=12 \mathrm{~mm}$ but different $\mathrm{D}$. When distance $\mathrm{D}=15 \mathrm{~mm}$, where the holes were close to the pre-crack tip, the holes had an influence on crack initiation, and the maximum compressive in the central zone of the connection line between the two holes increased as distance B decreased. When distance $\mathrm{D}=30$ or $\mathrm{D}=45$, the holes' influence on the pre-crack tip was limited, and the maximum compressive stress slightly increased. Thus, the compressive stress was sensitive to the two holes' locations, especially distance $B$, while the maximum compressive stress in the central zone of the connection line between the two holes was a crucial index in determining the holes' influence.

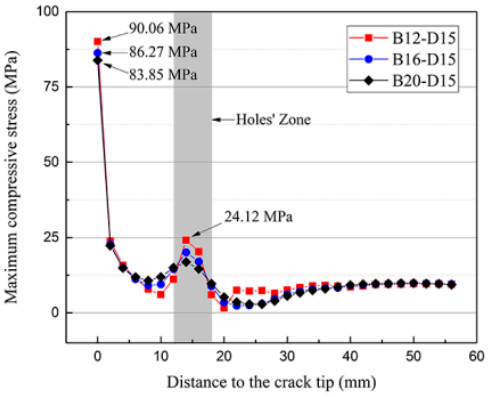

(a)

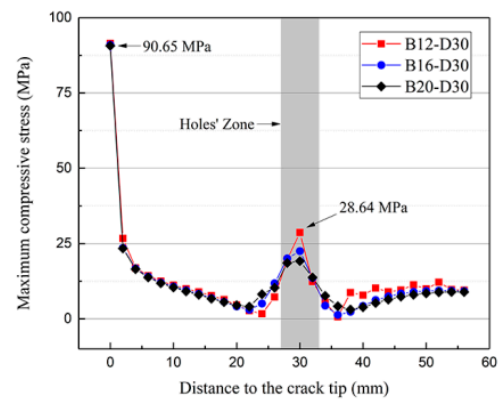

(b)

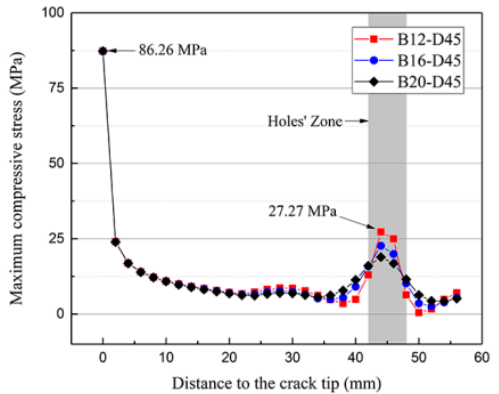

(c)

Figure 15. Numerical (AUTODYN) results of maximum compressive stress curves. (a) Specimens with a constant distance of $\mathrm{D}=15 \mathrm{~mm}$. (b) Specimens with a constant distance of $\mathrm{D}=30 \mathrm{~mm}$. (c) Specimens with a constant distance of $\mathrm{D}=45 \mathrm{~mm}$.

\section{Conclusions}

The effect of the holes on dynamic crack propagation was investigated using a experimental-numerical method. SHPB experiments were conducted with a crack propagation gauge 
test system, and the finite difference code AUTODYN was applied in determining the mechanism of the holes' effect. The conclusions are listed below.

1. The crack may be arrested by two symmetrical holes when propagating between the holes. Furthermore, the main crack may bifurcate to two sub-cracks and connect with the holes when the distance between the holes is very small, or the extending crack may be transitorily restrained by the holes when the propagation velocity decreases sharply.

2. The effect of the holes has a sensitive relationship with the distance between the holes and the distance of the holes to the crack tip.

3. The effect of the holes is dependent on the compressive stress field caused by the deformation of the holes during the crack propagation process. Moreover, the compressive stress perpendicular to the crack is the dominant factor influencing the crack propagation behavior.

4. The finite difference code AUTODYN has an advantage in solving dynamic fracture problems, and it can be applied in investigating the crack propagation behavior of brittle materials.

Author Contributions: Conceptualization, F.W. and M.W.; methodology, F.W. and M.W.; software, F.W. and M.W.; validation, F.W. and M.W.; formal analysis, F.W.; investigation, F.W.; resources, F.W. and M.W.; data curation, F.W. and M.W.; writing - original draft preparation, F.W.; writing-review and editing, F.W. and M.W.; visualization, F.W. and M.W.; supervision, M.W.; funding acquisition, M.W. All authors have read and agreed to the published version of the manuscript.

Funding: This research was funded by the National Natural Science Foundation of China (grant number 11702181), the China Postdoctoral Science Foundation (grant number 2016M602689), the Fundamental Research Funds for the Central Universities (grant number 2018SCU12047), and the China Scholarship Council (grant number 201806245024).

Conflicts of Interest: The authors declare no conflicts of interest.

\section{References}

1. Gómez, F.J.; Elices, M.; Berto, F.; Lazzarin, P. Local strain energy to assess the static failure of U-notches in plates under mixed mode loading. Int. J. Fract. 2007, 145, 29-45. [CrossRef]

2. Cook, N.G.W. Natural joints in rock-mechanical, hydraulic and seismic behavior and properties under normal stress. Int. Rock Mech. Min. Sci. Geomech. Abstr. 1992, 29, 198-223. [CrossRef]

3. Soh, A.K.; Yang, C.H. Numerical modeling of interactions between a macro-crack and a cluster of micro-defects. Eng. Fract. Mech. 2004, 71, 193-217. [CrossRef]

4. Mishuris, G.; Movchan, A.; Movchan, N.; Piccolroaz, A. Interaction of an interfacial crack with linear small defects under out-of-plane shear loading. Comput. Mater. Sci. 2012, 52, 226-230. [CrossRef]

5. Simonov, I.V.; Karihaloo, B.L. Dislocation model of an asymmetric weak zone for problems of interaction between crack-like defects. Philos. Mag. 2005, 85, 1847-1864. [CrossRef]

6. Jiang, C.; Zhao, G.F.; Zhu, J.B.; Zhao, Y.X.; Shen, L.M. Investigation of Dynamic Crack Coalescence Using a Gypsum-Like 3D Printing Material. Rock Mech. Rock Eng. 2016, 49, 3983-3998. [CrossRef]

7. Gao, D.W.; Zhang, C.W. Theoretical and numerical investigation on in-plane impact performance of chiral honeycomb core structure. J. Struct. Integr. Maint. 2018, 3, 95-105. [CrossRef]

8. Zhang, C.W.; Gholipour, G.; Mousavi, A.A. Nonlinear dynamic behavior of simply-supported RC beams subjected to combined impact-blast loading. Eng. Struct. 2019, 181, 124-142. [CrossRef]

9. Theocaris, P.S.; Milios, J. Crack Arrest Modes of a Transverse Crack Going Through a Longitudinal Crack or a Hole. J. Eng. Mater. Technol. 1981, 103, 177-182. [CrossRef]

10. Milios, J.; Spathis, G. Dynamic interaction of a propagating crack with a hole boundary. Acta Mech. 1988, 72, 283-295. [CrossRef]

11. Murdani, A.; Makabe, C.; Saimoto, A.; Kondou, R. A crack-growth arresting technique in aluminum alloy. Eng. Fail. Anal. 2008, 15, 302-310. [CrossRef]

12. Ayatollahi, M.R.; Razavi, S.M.J.; Yahya, M.Y. Mixed mode fatigue crack initiation and growth in a CT specimen repaired by stop hole technique. Eng. Fract. Mech. 2015, 145, 115-127. [CrossRef]

13. Chen, N.Z. A stop-hole method for marine and offshore structures. Int. J. Fatigue 2016, 88, 49-57. [CrossRef] 
14. Yang, R.S.; Xu, P.; Yue, Z.W.; Chen, C. Dynamic fracture analysis of crack-defect interaction for mode I running crack using digital dynamic caustics method. Eng. Fract. Mech. 2016, 161, 63-75. [CrossRef]

15. Wang, Y.B.; Yang, R.S.; Zhao, G.F. Influence of empty hole on crack running in PMMA plate under dynamic loading. Polym. Test. 2017, 58, 70-85. [CrossRef]

16. Zhu, Z.; Mohanty, B.; Xie, H. Numerical investigation of blasting-induced crack initiation and propagation in rocks. Int. J. Rock Mech. Min. Sci. 2007, 44, 412-424. [CrossRef]

17. Zhu, Z. Numerical prediction of crater blasting and bench blasting. Int. J. Rock Mech. Min. Sci. 2009, 46, 1088-1096. [CrossRef]

18. Wang, M.; Zhu, Z.; Dong, Y.; Lei, Z. Study of mixed-mode I/II fractures using single cleavage semicircle compression specimens under impacting loads. Eng. Fract. Mech. 2017, 177, 33-44. [CrossRef]

19. Wang, M.; Wang, F.; Zhu, Z.; Dong, Y.; Mousavi Nezhad, M.; Zhou, L. Modelling of crack propagation in rocks under SHPB impacts using a damage method. Fatigue Fract. Eng. Mater. Struct. 2019, 42, 1699-1710. [CrossRef]

20. Zhu, Z.; Chao, W.; Kang, J.; Li, Y.; Meng, W. Study on the mechanism of zonal disintegration around an excavation. Int. J. Rock Mech. Min. Sci. 2014, 67, 88-95. [CrossRef]

21. Zhang, Q.B.; Zhao, J. A Review of Dynamic Experimental Techniques and Mechanical Behaviour of Rock Materials. Rock Mech. Rock Eng. 2014, 47, 1411-1478. [CrossRef]

22. Shin, H.; Kim, D. One-dimensional analyses of striker impact on bar with different general impedance. Proc. Inst. Mech. Eng. Part C J. Eng. Mech. Eng. Sci. 2019. [CrossRef]

23. Wang, X.; Zhu, Z.; Meng, W.; Peng, Y.; Lei, Z.; Dong, Y. Study of rock dynamic fracture toughness by using VB-SCSC specimens under medium-low speed impacts. Eng. Fract. Mech. 2017, 181, 52-64. [CrossRef]

24. Rossmanith, H.P.; Daehnke, A.; Knasmillner, R.E.; Kouzniak, N.; Ohtsu, M.; Uenishi, K. Fracture mechanics applications to drilling and blasting. Fatigue Fract. Eng. Mater. Struct. 1997, 20, 1617-1636. [CrossRef]

25. Yue, Z.W.; Yang, L.Y.; Wang, Y.B. Experimental study of crack propagation in polymethyl methacrylate material with double holes under the directional controlled blasting. Fatigue Fract. Eng. Mater. Struct. 2013. [CrossRef]

26. Eringen, A.C.; Suhubi, E.S.; Chao, C.C. Elastodynamics, Vol. II, Linear Theory. J. Appl. Mech. 1978, 45, 229. [CrossRef]

27. Wang, Q.Z.; Yang, J.R.; Zhang, C.G.; Zhou, Y.; Li, L.; Wu, L.Z.; Huang, R.Q. Determination of Dynamic Crack Initiation and Propagation Toughness of a Rock Using a Hybrid Experimental-Numerical Approach. J. Eng. Mech. 2016, 142, 9. [CrossRef]

(C) 2020 by the authors. Licensee MDPI, Basel, Switzerland. This article is an open access article distributed under the terms and conditions of the Creative Commons Attribution (CC BY) license (http://creativecommons.org/licenses/by/4.0/). 